\title{
La contribución de "El Príncipe" de Maquiavelo para la comprensión de la Política Exterior Brasileña del siglo XXI
}

\section{The contribution of "The Prince" of Machiavelli to understand the Brazilian Foreign Policy of the XXI century}

\section{FABRICIO PADILHA PEREIRA DA SILVA ${ }^{1}$}

Resumen: A principios del siglo XXI la imagen del Brasil se proyecta en el ámbito internacional a través de los elementos estratégicos y diplomáticos más pragmáticos. Varios objetivos se relacionan directamente con la idea de ganar, querer y mantener el poder, como usar la política exterior del país como un mecanismo de desarrollo socio-económico, priorizar las relaciones con los países del Mercosur, fortalecer el multilateralismo y la creación de nuevas coaliciones, fortalecer el aspecto político brasileño en el orden mundial, etc. Una especie de pragmatismo que no renuncia a sus principios y valores. El objetivo del texto es a través de la lectura de "El Príncipe" de Maquiavelo responder la siguiente pregunta: ¿Qué pragmatismos están insertados en la Política Exterior de Brasil cuando el país actúa de acuerdo con los principios del multilateralismo, cooperación y universalismo?

Palabras claves: Política Exterior de Brasil. Maquiavelo. Pragmatismo.

\begin{abstract}
At the beginning of XXI century Brazil's image is projected internationally through strategic and diplomatic elements more pragmatic. Several objectives are directly related to the idea of winning, wishing, and keeping power, such as using foreign policy as a means of socio-economic development, prioritizing relations with the Mercosur countries, strengthening multilateralism and the creation of new coalitions, strengthening the Brazilian political aspects in the World Order, etc.. A kind of pragmatism that does not renounce its principles and values. The objective of the text is, through the reading of "The Prince" by Machiavelli, to answer the following question: What pragmatisms are inserted in the Brazilian Foreign Policy when this country acts according to the principles of multilateralism, cooperation and universalism?
\end{abstract}

Keywords: Brazil's Foreign Policy. Machiavelli. Pragmatism.

\footnotetext{
${ }^{1}$ PhD Candidate en Ciência Política por la Universidade Estadual de Campinas - UNICAMP. Endereço para correspondência: Universidade Estadual de Campinas, Instituto de Filosofia e Ciências Humanas, Rua Cora Coralina, s/n - CEP: 13083-896 - Cidade Universitária, Campinas/SP. Email: fabapps@hotmail.com
}

Recebido em 16 de fevereiro de 2014 Aceito em 07 de abril de 2014

Received on February 16, 2014

Accepted on April 7, 2014

DOI: $10.12957 /$ rmi.2014.9471 


\section{Consideraciones iniciales}

Nicolás Maquiavelo (1469 - 1527) fue uno de los primeros, sino el primero pensador político más conocido de la era cristiana, que examinó sistemáticamente las condiciones necesarias para la existencia del poder y la supervivencia en la política. $\mathrm{Su}$ mayor contribución fue intentar demostrar que la política y la moral no son intrínsecas, mientras que dejó claro que no son mutuamente excluyentes. Sin embargo, para el pensador, los principales fundamentos de cada estado son las buenas leyes y las buenas armas: no se puede tener buenas leyes sin buenas armas, y donde hay buenas armas, inevitablemente existen buenas leyes (Maquiavelo, cap. XII). De acuerdo con la interpretación de Ames (2011), para Maquiavelo en "El Príncipe", el enemigo es definido como aquellos que no son amigos ni aliados, y contra los enemigos casi todo está permitido. Orden y desorden no son mutuamente excluyentes, sino que una presupone la otra. Orden es sólo una posibilidad y no una necesidad, porque el conflicto puede generar una $u$ otra. Porque el hombre actúa por elección o por necesidad, y la ambición y el deseo son las tendencias inherentes a todos los hombres.

"El Príncipe", su libro más importante, está en su aniversario de 500 años, haciendo apropiado analizar a través de la obra, aunque sea superficialmente, una lectura contemporánea de la política exterior brasileña. Además, queda clara la tendencia del autor para un análisis de política exterior. Por ejemplo, en el capítulo décimo noveno del libro, Maquiavelo advierte que "la situación interna, no perturbada por una conspiración, estará a salvo cuando la externa se estabiliza." Para la estabilización del país es necesario conocer la situación externa, así como el deseo por la participación o incluso controlar este escenario. Por otra parte, se recomienda al Príncipe tener cinco cualidades, tales como, ser piadoso, fiel, humano, recto y religioso (Maquiavelo, Cap. XVIII).

La pregunta de partida es: ¿Cuál es la contribución de "El Príncipe" para un análisis de política exterior de Brasil (PEB) de la primera década del siglo XXI? De hecho, tener una lectura de la PEB desde la perspectiva de "El Príncipe" ofrecerá una serie de preguntas coherentes a la realidad actual del país. Al leer el libro, preguntas como "¿La política exterior depende de la voluntad o de la circunstancia?", "¿Es Brasil o el contexto internacional que determina el comportamiento del país?", "¿A qué / quién Brasil teme?", "¿A qué / quién Brasil es coaccionado/coacciona?", ¿De quién Brasil toma su modelo de actuación?”, "¿Por quién Brasil es admirado?", "¿A quién Brasil intenta persuadir?" son inevitables. Muchas otras cuestiones son abiertas, pero el objetivo es responder la siguiente: ¿Qué pragmatismos están insertados en la Política Exterior de Brasil cuando el país actúa de acuerdo con los principios del multilateralismo, cooperación y universalismo?

\section{Proyección de poder en la Política Exterior Brasileña}

La Política Exterior de Brasil a principios del siglo se ha vuelto más firme en las relaciones con el Norte, y más actuante con el Sur. Brasil ha logrado incrementar su presencia en el Sur y establecer relaciones más allá del comercio, tornando visible la complementariedad posible y el éxito entre los países emergentes. Tal vez Maquiavelo podría decir que Brasil puede estar entrando en el club de las potencias, contrastando a la propia falta de recursos que el país vive para oponerse al orden. Al hacerse mayor, 
la idea sería "convertirse en jefe y defensor de los menos fuertes, tratando de debilitar a los poderosos y cuidando que en ningún caso penetre un extraño tan fuerte" (Maquiavelo, cap. III), sobre todo porque "es necesario que un príncipe tenga el pueblo como un amigo, porque de lo contrario no tendrá posibilidades en la adversidad" (Maquiavelo, cap. IX).

Si la década de 1990 representó el retorno de la relación bilateral - hemisférico, el siglo XXI ha traído una demanda por una tradición global - multilateral, lo que trajo una evolución a través de la convergencia de los niveles bilaterales y multilaterales de la política exterior, centrándose en la expansión y la combinación de las dimensiones horizontales y verticales de las alianzas estratégicas (Pecequilo, 2008). Como Oliveira (2005, p.2) establece:

\begin{abstract}
A diplomacia brasileira sob o governo Lula aprofundou a correção de rota iniciada em fins do segundo mandato de Cardoso. Imediatamente após suas posses, Lula e Amorim declararam ser necessário reinterpretar as premissas clássicas da política externa brasileira, dando a elas um novo sentido. O objetivo sería garantir a sustentação de uma estratégia de inserção internacional do país diferente daquela presente na maior parte do governo Cardoso e que fosse mais adequada às demandas das novas elites econômicas, das coalizões sociais e políticas no poder, da percepção do papel a ser ocupado pelo Estado brasileiro no mundo e dos constrangimentos internacionais à inserção periférica dos países em desenvolvimento.
\end{abstract}

Cuatro objetivos directamente relacionados con la idea de ganar, mantener y desear poder son claramente explícitos en la Política Exterior de Brasil, como el uso de la política exterior del país como mecanismo para el desarrollo socioeconómico nacional, que se ajusta a la búsqueda de nuevos destinos de exportación y acuerdos a las nuevas tecnologías, la priorización de las relaciones con otros países de Sudamérica, especialmente con el Mercosur, el fortalecimiento del multilateralismo sobre la creación de nuevas coaliciones con el fin de reducir las desigualdades en el proceso de toma de decisiones internacionales, el fortalecimiento político brasileño en el orden global. etc.

Según Miyamoto (2011), en las relaciones internacionales, los recursos tradicionales de poder son la extensión territorial, la población apreciable, los recursos naturales, las fuerzas militares razonables e inversión en la ciencia y la tecnología. Un Estado generalmente tiene poder cuando es capaz de conocer a sus vecinos, de interferir en los asuntos internos de otros países e influenciar en la toma de decisiones en las instituciones multilaterales. Para Maquiavelo, el potencial de un estado es entendido por la racionalidad de la aplicabilidad de los recursos de poder constituidos por estrategias que utilizan la fuerza y la inteligencia. Para él, "necesitando un príncipe, y, por lo tanto, conociendo bien emplear el animal, éste debe tomar como modelo el zorro y el león, porque éste no defiéndele de las ataduras y aquel no tiene defensa contra los lobos. Es necesario, por lo tanto, ser zorro para conocer los lazos y también ser león para atemorizar a los lobos. Los que actúan solo como el león no conocen su arte" (Maquiavelo, cap. XVIII).

Históricamente, las relaciones brasileñas en el comercio y en las relaciones políticas internacionales se establecían en una dimensión vertical, cuya diversificación siempre ocurrió entre Europa y Estados Unidos. Muchas de las iniciativas del gobierno de Lula da Silva (2003 - 2010) seguían las negociaciones comerciales internacionales y la coordinación de políticas con los países en desarrollo y las economías emergentes, en particular la 
India, Sudáfrica, China y Rusia. Las relaciones con América del Sur también merecen atención, pero ya se hicieron explícitas en la política exterior del gobierno de Fernando Henrique Cardoso (1995 - 2002), intensificando el discurso de la globalización asimétrica (Pecequilo, 2008). Para Vigevani y Cepaluni (2007, p. 283), el presidente Lula da Silva buscó introducir el país en el escenario mundial a través:

\begin{abstract}
Da adesão aos princípios e às normas internacionais por meio de alianças Sul-Sul, inclusive regionais, e de acordos com parceiros não tradicionais (China, Ásia-Pacífico, África, Europa Oriental, Oriente Médio etc.), pois se acreditou que eles reduzem as assimetrias nas relações externas com países mais poderosos e aumentam a capacidade negociadora nacional.
\end{abstract}

Menezes (2008) estima que la Política Exterior brasileña puede ser considerada como un instrumento político-estratégico para la realización de los objetivos nacionales relacionados con la gestión económica y de desarrollo. Los instrumentos adoptados - en especial la estrategia de coaliciones internacionales para fortalecimientos de las posiciones de negociación brasileñas - están, en el mismo sentido, condicionados a los resultados y a las consecuencias de la agenda de negociaciones... [internacionales]. La PEB también reconoció la importancia y relevancia de la formación de coaliciones (sur-sur) en el proceso de negociaciones para aumentar la influencia y articulaciones de los países en desarrollo.

En "El Príncipe" y en esta misma lógica, para Maquiavelo "nunca existió un joven príncipe que desarmó a sus súbditos, sino que, cada vez que los encontró desarmado, los armó. Esto se debe a que, al armarlos, esas armas se convierten en suyos, se hacen creyentes aquellos que eran sospechosos, los que eran fieles se mantienen así, y los súbditos se convierten en partidistas"
(Maquiavelo, cap. XX). Así, Brasil pretende armar, lo que puede ser entendido como la provisión de recursos tales como la cooperación económica y la coordinación política, a los países que habían mantenido relaciones históricas, así como proyectar los intereses comunes y crear grupos de presión con los nuevos actores internacionales.

\section{Maquiavelismo y los Principios de la Política Exterior de Brasil}

Como afirma Amorim (2010), Brasil actúa pragmáticamente, pero no renuncia a sus valores y principios de la política internacional del país. La pregunta que se plantea es, ¿La idea de pragmatismo de la PEB es excluyente a la defensa de sus valores? Lo que se cree es que la política exterior brasileña actúa pragmáticamente sin renunciar a sus principios, ya que estos también son pragmáticos. Siguen a continuación, breves análisis de los tres principios que consideramos pragmáticos: el multilateralismo, la cooperación y el universalismo.

Multilateralismo parte del objetivo de ayudar a garantizar la estabilidad sistémica. Para Souto Maior (2004), la estabilidad del Sistema Internacional depende del apoyo efectivo de los Estados y de los beneficios percibidos como equitativos. Según Baracuhy (2006), para la elite brasileña formuladora de la política exterior, la búsqueda por una posición de poder central en el tablero multilateral fue decisivo en la definición de la estrategia general del país, orientando sus estrategias y tácticas diplomáticas para el nuevo orden en el post Primera Guerra Mundial. No obstante, en el siglo XXI hay un cambio en el modo de participación de los países intermedios en este tipo de mecanismo. Esto es porque según Mello (2011, p.18): "tanto na OMC, quanto em Copenhague, ou na irrelevância da Assembleia Geral da ONU, o 
multilateralismo democrático... garantindo o mesmo direito a voto para todos, passa a constituir... fator de paralisia... porque confere o mesmo status aos pequenos países e potências."

A pesar de ser identificada esta parálisis en el multilateralismo comercial, otros espacios multilaterales son dinamizados en la política exterior. Para Saraiva (2010), a partir de 2008, el Ministerio de Relaciones Exteriores (MRE - Brasil) ha buscado aprovechar todos los espacios abiertos por su nueva clasificación internacional de país BRIC y ha participado activamente en los foros multilaterales como el G-7 (como país invitado), en las negociaciones sobre medio ambiente, actuando un papel activo en el G20 de la Organización Mundial del Comercio (OMC) (juntamente con India, China y Sudáfrica), y en la Unasur. Según Doval (2010), Brasil pasó a entender el multilateralismo, de la misma forma que otros países del Sur, a partir de una estrategia defensiva, con el fin de evitar las interferencias de los países desarrollados, generando así, una cierta autonomía.

Como puede ser visto en la actuación del país después de la Guerra Fría, Brasil incluyó iniciativas privadas de inserción internacional que podrían clasificarse como ofensiva, principalmente con sus relaciones con Sudáfrica, India y China, acerca de la reforma del Consejo de Seguridad de las Naciones Unidas y en relación a la eliminación de los subsidios agrícolas de los países desarrollados a través de de la Organización Mundial del Comercio. En relación al Fondo Monetario Internacional, por ejemplo, a fin de permitir una participación más activa en los procesos de decisiones, Brasil busca una actuación conjunta con los otros países BRICS para obtener una distribución de cuotas para superar el 1,5\% del total. Caso este objetivo sea alcanzado, ellos conseguirían a través de una posición común algo más allá del poder de veto en la Institución (Ferracioli, 2010).

La Política Exterior en el inicio de siglo XXI reconoció la importancia y relevancia de la formación de coaliciones (Sur-Sur) en el proceso de negociaciones para aumentar la influencia de los países en desarrollo. Es de destacar que la especificidad del gobierno, especialmente del presidente Lula da Silva, insistió, según Veiga (2006), en tres líneas de cambios en las negociaciones internacionales: en primer lugar, las negociaciones preferenciales con los países del Norte han perdido peso en la estrategia del gobierno; en la segunda línea, a partir de 2003, adquirieron relevancia a la estrategia de Brasil las negociaciones con otros países en desarrollo, cuyos dos elementos están presentes en la reactivación de las negociaciones políticas en la dimensión Sur-Sur - el Mercosur y el IBSA; y en tercer lugar, la pérdida de importancia de las negociaciones con los países desarrollados y la creciente importancia de las relaciones Sur-Sur se añadieron al peso cada vez mayor que las demandas de la liberalización agrícola tomaron en la agenda comercial de Brasil.

La Cooperación ha sido desde los años 1990 un factor constitutivo de la PEB. La alta prioridad del país fue, entonces, la aceleración de la integración del Mercosur. Después de la llegada de Fernando Henrique Cardoso a la presidencia de la República, la cooperación internacional ha sido un tema constante en el discurso y en la acción del país (Miyamoto, 2011). En cuanto a la cooperación técnica, desde los años 1970, Brasil comienza diferenciarse de los países del Sur en términos de desarrollo económico, pasando de receptor a proveedor de este tipo de cooperación. Como Pino y Leite (2010, p.21) se refieren: "las iniciativas de ayuda exterior no parecen restringirse a su ámbito propio, sino que configuran un instrumento de política 
exterior en la medida que se incluyen objetivos estratégicos para una mayor inserción internacional, política y económica de Brasil.”

Sin embargo, la cooperación brasileña parece flotar por un contexto muy estratégico por dos razones: en primer lugar por la búsqueda de un asiento permanente en el Consejo de Seguridad de la Organización de las Naciones Unidas, y en segundo lugar para difundir la producción mundial de biocombustibles, la tecnología, las ventas de materias primas, maquinaria y equipos producidos de las empresas nacionales. Por otra parte, la cooperación brasileña como instrumento de la política exterior desempeña tres funciones nacionales: la salvaguardia de los intereses del país, la competencia por los mercados y el logro de prestigio.

No obstante, para Doval (2010), la cooperación Sur-Sur es esencialmente política, cuyo objetivo sería reforzar las relaciones bilaterales $\mathrm{y} / \mathrm{o}$ fortalecer las coaliciones en los foros multilaterales, para lograr una mayor capacidad de negociación conjunta. Por otra parte, Nogueira (2009) añade que la cooperación Sur-Sur es parte de la estrategia de cambio de tamaño de la posición brasileña, para hacer del país un líder regional más fuerte y presente, ampliando sus posibilidades de acción frente a las restricciones y limitaciones impuestas por el Sistema Internacional. Las relaciones entre estos países proporcionan pruebas de que las complementariedades entre ellos pueden ser más grandes que los factores de la competición. Como países intermedios ellos ya tienen una base industrial compleja, que alcanza un relativo desarrollo tecnológico en algunos sectores líderes. Por otro lado, también comparten todos los problemas estructurales del tercer mundo: la pobreza, la desigualdad y el analfabetismo (Lima, 2005).
El universalismo es también un principio constitutivo de la PEB. Además de significar una libertad de acción en relación con la potencia hegemónica, y estar ligado al comportamiento de global player, el universalismo está abierto a mantener relaciones con todos los países, independientemente de su ubicación geográfica, tipo de régimen y la opción económica (Saraiva, 2010). Brasil ha puesto en relieve aún más este principio cuando necesitó justificar dos cosas: el país ha utilizado en el caso de la misión de paz en Haití, liderada por Brasil, cuyo canciller Celso Amorim acuñó el término "no indiferencia" como contrapunto a "no intervención" para justificar la participación en la misión (Lima, 2005). Por otra parte, para justificar sus intereses en las relaciones con los más recientes y con los países de Oriente Medio. En 2009, por ejemplo, Brasil recibió la visita de algunos de los principales actores en el conflicto en el Medio Oriente, como los presidentes de Irán, Israel y la Autoridad Palestina, y el presidente de Brasil de la época viajó a Israel, Jordania y Palestina. Además, se alió con Turquía en 2010 para proponer junto con Irán el Acuerdo de Teherán, cuyo objetivo era llevar a este país a volver a las negociaciones sobre su programa nuclear con la comunidad internacional.

Como señala el profesor Miyamoto (2011, p.9): "o país [o Brasil] se situa em uma concepção prévia, existente, orientada e voltada para o mundo ocidental, ainda que elabore uma retórica universalista". Saraiva (2010) concluye que la orden está motivada tanto por iniciativa de Brasil para consolidar el liderazgo en la región y el posible aumento del peso del país en la escena internacional. Además, que el mecanismo de negociación por el eje diplomático sea comprensible. Como Biato (2010) sugiere, Brasil casi siempre se ha cuestionado la eficacia de las sanciones a través del diálogo. Las experiencias del 
pasado, como el embargo a Cuba, sugieren que empujar a Irán contra la pared, en las palabras del ex presidente Lula, sería contraproducente.

Preguntase ¿La participación de Brasil en este escenario ayuda promover la paz y la prosperidad en el Medio Oriente? Una respuesta posible sería “... como poderia o Brasil justificar sua candidatura ao Conselho de Segurança das Nações Unidas se não se empenhasse pela em região sujeita a potencialmente desastrosa crise política com consequências bélicas e imprevisíveis" (Biato 2010, p.5).

\section{Consideraciones finales}

En resumen, la política exterior brasileña en este siglo requiere una interpretación cada vez más pragmática. La proyección internacional del país a través de su política exterior ha sido sostenida por el poder de la persuasión y mediación, la defensa y la preservación de los derechos humanos y la consolidación de la democracia, la búsqueda de una estrategia para fortalecer la economía de mercado, la adhesión al régimen internacional de no proliferación de armas de destrucción masiva, la defensa del medio ambiente, etc. Son imágenes, status, funciones y articulaciones políticas que muestran el agotamiento del paradigma americanista a favor de una política exterior "más pragmática y firme" (Jesus, 2010), o que muestran el corte "diplomático creativo y pragmático" (Coutto, 2010), demandante de una inserción en los escenarios internacionales que acentúan actuaciones más autónomas, que diversifican los socios y las opciones estratégicas (Vigevani y Cepaluni, 2007). Una actuación de los "intereses con pragmatismo, sin renunciar a los principios y valores" (Amorim, 2010). Principios que a pesar de los cambios naturales que se han impuesto en diferentes coyunturas permanecieron en parámetro básico (Miyamoto, 2011).

En un aspecto más analítico a cerca de la conducta de Brasil a la luz de las enseñanzas de Maquiavelo, tengamos en cuenta algunos puntos importantes. En primer lugar, llamamos la atención para el dilema brasileño marcado por su real situación de un país no-potencia, principalmente en términos de poder rígido, de un lado, y su deseo implícito y explícito de tener más poder en términos de poder rígido y blando a través de su constante búsqueda de inserción y auto-promoción, por medio de alianzas, asociaciones, instituciones, integración económica, ciencia y tecnología, y diplomacia pública, por otro. Al poder rígido, el león de Maquiavelo, nos referimos a la coerción, convicción, comando, pagos, sanciones, y soborno. Y poder blando, la zorra de el pensador, nos referimos a la composición de la agenda, cultura, cooptación, instituciones, valores, y atracción.

En segundo lugar, el deseo de Brasil por el poder es doble. Por un lado, está la promoción del estado brasileño envuelto a los más poderosos en términos políticos y económicos, y por otro, hay una autodesignación de país fuerte y también de representante de los países débiles, especialmente en términos económicos. En tercer lugar, su auto-designación como representante de los más débiles tiene un interés estratégico a largo plazo. Tal como los países desarrollados recurren a los emergentes en tiempos de crisis, esta estrategia brasileña es real, partiendo de este punto de vista, principalmente por factor de prudencia y conveniencia.

En cuarto lugar, Brasil ha puesto en marcha proyectos destinados a la defensa nacional y la seguridad regional. Sin embargo, aunque no existe una fuerte capacidad material (las tradicionales, como el armamento y su tecnología militar), el país utiliza la 
representados. Sus clubes, como IBSA, BRIC, OPLP, incluso sus proyectos de construcción de puertos en Cuba y Uruguay son ejemplos prácticos de esto.

\section{Referencias}

Ames, J. L. (2011). 'Lei e violência ou a legitimação da política em Maquiavel'. Trans/Form/Ação, Marília, 34 (1), pp. 21-42.

Amorim, C. (2010). 'Brazilian Foreign Policy under President Lula (2003 - 2010): an overview'. Revista Brasileira de Política Internacional, n.53 (Special Edition), pp. 214 - 240.

Baracuhy, B. (2006). 'A crise da Liga das Nações de 1926: Realismo Neoclássico, Multilteralismo e a natureza da Política Externa Brasileira'. Contexto Internacional, Rio de Janeiro, 28(2), pp. $355-397$.

Biato, M. F. (2010). 'Brasil, Irã e Paz no Oriente Médio'. Mural Internacional, Rio de Janeiro, $1(2)$, pp. $2-6$.

Coutto, T. (2010). 'Global Governance: Brazilian Views from Cardoso to Lula'. Mural Internacional, Rio de Janeiro, 1(2), pp. $43-49$.

Doval, M. G. P. (2010). 'La cooperación Sur-Sur: Argentina y Brasil: dos interpretaciones diferentes'. Mural Internacional, Rio de Janeiro, 1(1), pp. 40 - 44.

Jesus, D. S. V. de (2010). "Esperando Godot? O Brasil e a China além da crise internacional". Mural Internacional, Rio de Janeiro, 1(2), pp. $36-42$.

Lima, M. R. S. (2005). 'Autonomia, Não-Indiferença e Pragmatismo: Vetores Conceituais da Política Exterior’. RBCE-LATN, n. 21, pp. $1-9$.

Maquiavelo, N. (1999). El Príncipe. Disponible em: http://www.elaleph.com/libro/El-Principede-Nicolas-Maquiavelo/704.

Mello, F. de C. (2011). 'O Brasil e o Multilateralismo Contemporâneo'. Texto para Discussão IPEA, n. 1628, Rio de Janeiro, pp. 1 - 32.

Menezes, H. Z. de (2008). 'Política Externa e Desenvolvimento Econômico na Gestão Lula'. IV Seminário de Ciência Política e Relações Internacionais da UFPE, Recife.

Miyamoto, S. (2011). 'As grandes linhas da Política Externa Brasileira'. Textos para Discussão CEPAL/IPEA, n.45, Brasília, pp. 1 - 34.

Nogueira, J. L. M. (2009). A articulação doméstica da burocracia brasileira para a implementação das ações do Fórum IBAS. Dissertação de Mestrado. Belo Horizonte: PUC-MG.

Oliveira, M. F. (2005). 'Alianças e Coalizões Internacionais do governo Lula: o Ibas e o G-20'. Revista Brasileira de Política Internacional, Brasília, 8(2), pp. 55 - 69. 


\section{Mural Internacional}

Pecequilo, C. (2008). 'A PEB no século XXI: os eixos combinados de cooperação horizontal e vertical'. Revista Brasileira de Política Internacional, Brasília, 51(2), pp. 136-153.

Pino, B. A.; Leite, I. C (2010). 'La cooperación Sur-Sur de Brasil: instrumento de política exterior y/o manifestación de solidariedad internacional'. Mural Internacional, Rio de Janeiro, $1(1)$, pp. $20-32$.

Saraiva, M. G. (2010). 'A diplomacia brasileira e as visões sobre a inserção externa Brasil: institucionalistas pragmáticos x autonomistas'. Mural Internacional, Rio de Janeiro, 1(1), pp. 45 -52 .

Souto Maior, L. A. P. (2004). 'A crise do multilateralismo econômico e o Brasil'. Revista Brasileira de Política Internacional, 47(2), pp.163-190.

Veiga, P. da M. (2006). 'As negociações comerciais sob Lula: a estratégia nacionaldesenvolvimentista repaginada'. Revista Brasileira de Comércio Exterior, n. 87.

Vigevani, T.; Cepaluni, G. (2007). 'A Política Externa de Lula da Silva: A estratégia da autonomia pela diversificação'. Contexto Internacional, Rio de Janeiro, 29(2), pp. 273 - 335. 